\title{
Independence in Decision Making: Considering the Distance between Parents and Their Children
}

\author{
Khushboo Kadam $^{1}$, Abhishek Bajpai ${ }^{2}$, J Balamurugan ${ }^{3}$
}

\section{ABSTRACT}

A survey was conducted to examine the strength of a relationship that develops over the years between children (confined to teenagers and those below 24 years of age) and parents who stay together with their children as well as those who don't. Also it was observed whether the distancing of children from the places they grew up and spent their childhood in after a particular age helped them become either independent or less dependent on their parents thus, helping them develop a more mature mentality than those staying with their parents. The survey was carried out in VIT University, Vellore, India selecting 60 day scholars (equivalent number of boys and girls) and 60 hostellers (equivalent number of boys and girls). Category specific sets of questionnaires were provided and the result was interpreted on the basis of the distance between parents and children and the decision making ability of an individual which directly affected the independency or dependency level of the child on his or her parents. The independent variable chosen here is distance between parent and children whereas the dependent variable taken is the independency in decision making ability observed in children.

Keywords: Relationship, Distancing, Behaviour, Dependency and Independency.

Lundberg et al. (2007) in their research paper on decision making by children observed that, a parent's control on the behaviour of young adolescents and their decision making abilities directly affects their maturity and independency in decision making. Distancing from parents after a particular age might have positive impacts in increasing confidence in the decisions they make. It is observed that children staying with their parents even after 18 years of age are more close to their parents and tend to depend upon them for small decisions. The control of parents in decision making of their child can be compared directly to the distance between them. The

\footnotetext{
${ }^{1}$ M.Sc. biotechnology student, School of Biosciences and Technology, VIT University, Vellore, Tamil Nadu, India

${ }^{2}$ M.Sc. biotechnology student, School of Biosciences and Technology, VIT University, Vellore, Tamil Nadu, India

${ }^{3} \mathrm{PhD}$, Assistant Professor, School of Social Sciences and Languages, VIT University, Vellore, Tamil Nadu, India *Responding Author

(C) 2016, K Kadam, A Bajpai, J Balamurugan; licensee IJIP. This is an Open Access Research distributed under the terms of the Creative Commons Attribution License (http://creativecommons.org/licenses/by/2.0), which permits unrestricted use, distribution, and reproduction in any Medium, provided the original work is properly cited.
} 
influence of decisions taken by adolescent teenagers is affected by their parent's views which are portrayed by them.

The Online Debate Society, also had a survey on the related topics which divided the decision making ability by adolescents in two major factors: The first one being whether the teenagers should be allowed to make their own decisions in which 57 percent of the participants supported the argument and believed that it boosted the independence in decision making and increased the confidence of teenagers in making legitimate decisions. Also when young adolescents take their own decision they tend to learn from their own mistakes which cut down the possibility of taking a wrong decision in a repetitive manner in future. They are less dependent on their parents or close relatives for their decision making. This ability is greatly boosted usually when they live far off from their parents and tend to rely on themselves for small and minor decisions. A major factor which develops in taking independent decisions is that no one can be blamed for inaccurate decisions. This thereby helps in development of a child's mature behaviour and he/she tends to make intelligent decisions in future. The distance being a major factor where in the parenting control becomes very less and thus it leads to more independent decisions. The second argument states that whether parents should allow their children to make their own decisions, where 63 percent of the participants agreed with the statement. Parents should give their children a chance to make minor decisions depending on the trust level with individual adult and thus then outcome of the decisions can be judged accordingly. The distance in this situation makes it compulsory for their parents to trust with their child's decision making ability which is not seen non-distance parenting.

Myatt (2012) in his article on 6 tips for making better decisions, he stated some important factors to make a successful decision based on some factors like calculating input information, type of decision to be made, risk factors and other several assessments. Sometimes decision depends on factors like gut feeling where emotional aspects come in play. He also described that the decisions made by people like leaders and businessman and their decisions which are affected by many external factors. Therefore, decisions taken should be balanced and not harmful for self as well as society and this can be done by keeping our decisions profitable to self as well as keeping different external factors in mind. A perfect balance in these factors leads to a very balanced and a good sensible decision. By Cook (2014), in his study on "Independence Decision Making" describes that independency in any decision increases quality of a decision made. But it is not realistic because people are influenced by many other factors while making a decision and therefore they are not able to frame a decision that is totally independent. He evens an example for testing it by asking a question that has to be answered in either yes or no and it suggested if the people would answer independently majority will answer that question correctly. Many good responses have come to this article and people have supported it and given their personnel views on it. 
In the book Psychological Self-Help under the chapter "Learning Independent Decision Making”, Tucker-Ladd (2004) highlighted_that parents and peer groups influence a decision made by a person. The Personnel Growth Model states that a decision can be framed in many ways. Some individuals are unsure of themselves and before each and every decision they think on what their parent would react if they were in the same situation. Some individuals just put off a decision whereas when some make their final decision to do nothing or not to react to the situation. Furthermore it was also discussed that when people in the age group 18 to 25 are asked to make sudden decisions with no prior history of independent decisions made before often panic and get highly confused in making independent decisions. The advices they get may be conflicting or may have no advices which majority of the times makes it even more difficult to make a final independent decision.

Patricket al. (2013) in their article titled "Decision making Processes and Outcomes", authors examined the individual characteristics which frame the quality of a decision. It described that various age groups have various thinking skills, mentality, experience, knowledge and input of information and therefore one's decision is based on such factors which vary for different age groups and personnel thinking as well as influence from external sources. Different age groups approach decision making with different goals applying different heuristics and therefore there is a vast difference of decision made by different age groups. The cognitive skill such as working memory and speed of processing were important factors to frame a final decision. The quality of information used on which your decision is made also influences the decision making ability of a person. However, same individual might use many forms of strategies in making a decision, the nature of response of which depends on complexity of the problem (Payne et al., 1993).

The study done here tries to signify the importance of independency in decision making in the adults (confined to teenagers below 24 years of age) who are living with their parents and who are living at a distance from their parents. It tries to detect the influence of parents on the children and how they frame their decisions. It also categorises the decisions made by adults in different situations, whether they are dependent on parents or independent or selfishness in decision made is seen. This study categorises adults in different categories depending on whether they stay with their parents or away and then take their personnel opinions on different situations that they have to make decisions and finally the results are shown on the options chosen by them in the specific categories.

\section{METHODOLOGY}

Before conducting the survey the questionnaire was tested with four known individuals; two hostellers: one male and one female\& two day scholars; one male and one female. This was done to check the authenticity of the questionnaire which was found to be appropriate. The survey was conducted with total 120 students in which equal number of males and females of both hostellers and day scholars were taken. Slides were shown which gave a pictorial hint about each question 
and their respective 3 options. Each question was given 30 seconds time limit so people would just give their generalized views without over thinking on the options provided. Different set of questionnaires were prepared for hostellers (long distance parenting) and day scholars (children staying with their parents) with 20 questions each. The questionnaire mainly focused on relation between individuals with their parents and their dependency on parents for decision making. Each question had 3 choices where the

i. High dependency of the individual on their parents in making decision.

ii. Independency shown by the person.

iii. Individual being selfish as they tend not to take advice or help form their elder ones to make their decisions.

To make it more easy hints were provided for each option stated. Privacy of the individual was maintained as no personnel information besides age and gender were asked.

\section{Data Analysis}

The following table 1 compares percentiles of the options chosen by hosteller participants. This gives an overall view about the Hosteller scenario that is the children or adolescent teenagers living with their parents.

Table 1: Percentage Distribution of independency in decision making by hosteller males and hosteller females

\begin{tabular}{|c|c|c|c|c|c|c|c|}
\hline \multirow{3}{*}{$\begin{array}{l}\text { Sl. } \\
\text { No. }\end{array}$} & \multirow{3}{*}{ Particulars } & \multicolumn{3}{|c|}{ Hosteller Males } & \multicolumn{3}{|c|}{ Hosteller Females } \\
\hline & & 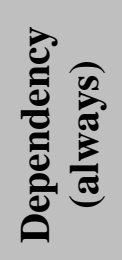 & 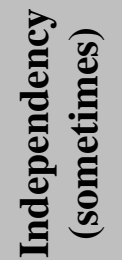 & 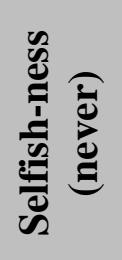 & 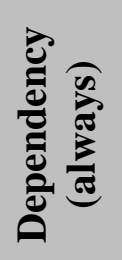 & 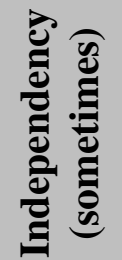 & 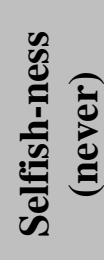 \\
\hline & & $\%$ & $\%$ & $\%$ & $\%$ & $\%$ & $\%$ \\
\hline 1 & Calling parents for advices & 50.0 & 26.7 & 23.3 & 46.7 & 33.3 & 20.0 \\
\hline 2 & Sharing of information & 13.3 & 60.0 & 26.7 & 36.7 & 56.6 & 06.7 \\
\hline 3 & Liking family surprise visit & 63.3 & 26.7 & 10.0 & 83.3 & 16.7 & 00.0 \\
\hline 4 & $\begin{array}{l}\text { Telling parents if caught in } \\
\text { malpractice }\end{array}$ & 40.0 & 36.6 & 23.4 & 36.6 & 40.0 & 23.4 \\
\hline 5 & $\begin{array}{l}\text { Inform parents about ill health } \\
\text { conditions }\end{array}$ & 30.0 & 50.0 & 20.0 & 46.6 & 46.6 & 06.8 \\
\hline 6 & Regularity of talks & 16.7 & 50.0 & 33.3 & 33.4 & 43.3 & 23.3 \\
\hline 7 & Influence of parents on decisions & 20.0 & 76.7 & 03.3 & 23.3 & 70.0 & 06.7 \\
\hline 8 & $\begin{array}{l}\text { Lying to parents about daily } \\
\text { activities }\end{array}$ & 33.3 & 63.4 & 03.3 & 20.0 & 80.0 & 00.0 \\
\hline 9 & $\begin{array}{l}\text { Connected with parents on social } \\
\text { media }\end{array}$ & 26.7 & 46.6 & 26.7 & 10.0 & 76.7 & 13.3 \\
\hline 10 & $\begin{array}{l}\text { Dealing with contrasting views and } \\
\text { agreeing with parents }\end{array}$ & 30.0 & 63.3 & 06.7 & 36.6 & 60.0 & 03.4 \\
\hline & AVERAGE & 32.3 & 50.0 & 17.7 & 37.3 & 52.3 & 10.4 \\
\hline
\end{tabular}

(c) The International Journal of Indian Psychology, ISSN 2348-5396 (e)| ISSN: 2349-3429 (p) | 113 
In the table 1, when seen for different categories when compared in between hosteller males that are the broader category which involves hosteller males we see 50 percent of them seek parental advices may or may not be on a daily basis. But on a contrary when it comes to sharing of information 60 percent of the hosteller males chose to be independent there can be many causes which might be involved in this decision of sharing information and independency related to it. Hostellers in this survey were seen to seek a positive impact on family surprise visit this point cannot be considered as an independency phenomenon but a proving point that even when independency is observed in the other cases a connection with the family is maintained by these individuals as the percentile rises to 63.3 percent. When it comes to telling parents about malpractices which were done a very slight difference was observed between the dependent and the independent group which was 40 percent and 36.6 percent respectively. Whereas 50 percent of the people were seen independent in the aspect of regularity in talking with parents and informing their far living parents of the ill health conditions. On the other hand a very high portion that is 76.7 percent of the hosteller males was independent of the decisions whereas only 3.3 percent preferred lying to parents. However, 63.3 percent of hosteller males preferred dealing with the contrasting views in a why so that practically feasible decisions are followed. In this way a 50 percent independency was observed in hosteller males on a contrary 17.7 percent preferred only their decisions to be followed may it be feasible or not.

When seen in hosteller femalesa different case was observed where only 46.7 percent of the population were seen to seek parental advice whereas a high grade of independency was seen when the point of sharing information with parents were raised 56.6 percent of the females were seen to be independent. Moreover, 83.3 percent females supported the idea of surprise family visit as mentioned earlier. Only 23.4 percent preferred not involving parents when caught in malpractices on the contrary 6.8 percent did not tell about their ill health conditions which indicated majority involved parents in health condition issues. None of them were seen to lying 80 percent of independency rate was seen in this case. However, 60 percent independency was observed when the points of dealing with contrasting views were raised.

The following table 2 compares percentiles of the options chosen by day scholar participants this gives an overall view about the day scholar scenario that is the children or adolescent teenagers living with their parents. 
Table 2: Percentage Distribution of independency in decision making by day scholar males and day scholar females

\begin{tabular}{|c|c|c|c|c|c|c|c|}
\hline \multirow[b]{2}{*}{$\begin{array}{l}\text { Sl. } \\
\text { No. }\end{array}$} & \multirow[b]{2}{*}{ Particulars } & \multicolumn{3}{|c|}{ Day Scholar Males } & \multicolumn{3}{|c|}{ Day Scholar Females } \\
\hline & & 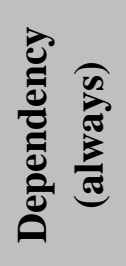 & 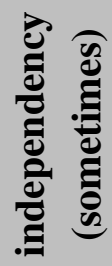 & 总 & 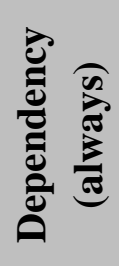 & 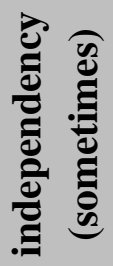 & 总 \\
\hline 1 & $\begin{array}{l}\text { Telling parents if caught in } \\
\text { malpractice }\end{array}$ & 13.3 & 40.0 & 46.7 & 30.0 & 53.3 & 16.7 \\
\hline 2 & $\begin{array}{l}\text { Discussing friend time plans with } \\
\text { parents }\end{array}$ & 50.0 & 36.7 & 13.3 & 36.7 & 60.0 & 03.3 \\
\hline 3 & Lying to parents & 10.0 & 76.7 & 13.3 & 13.3 & 76.7 & 10.0 \\
\hline 4 & Time is spent with family & 36.7 & 43.3 & 20.0 & 46.7 & 33.3 & 20.0 \\
\hline 5 & $\begin{array}{l}\text { Sharing of detailed information with } \\
\text { parents }\end{array}$ & 33.3 & 66.7 & 10.0 & 30.0 & 46.7 & 33.3 \\
\hline 6 & $\begin{array}{l}\text { Sharing the work load with parents } \\
\text { during functions }\end{array}$ & 53.3 & 43.3 & 03.3 & 40.0 & 36.7 & 23.3 \\
\hline 7 & Introducing friends to parents & 40.0 & 13.3 & 46.7 & 60.0 & 33.3 & 06.7 \\
\hline 8 & $\begin{array}{l}\text { Choosing to spend time with family } \\
\text { over friends }\end{array}$ & 40.0 & 13.3 & 46.7 & 30.0 & 16.7 & 53.3 \\
\hline 9 & $\begin{array}{l}\text { Feeling of privacy invasion with } \\
\text { parents around }\end{array}$ & 53.3 & 40.0 & 06.7 & 33.3 & 36.7 & 30.0 \\
\hline 10 & $\begin{array}{l}\text { Feeling of parents being a help } \\
\text { during critical conditions }\end{array}$ & 50.0 & 300 & 20.0 & 66.6 & 16.7 & 16.7 \\
\hline & AVERAGE & 38.0 & 40.0 & 22.0 & 38.7 & 40.0 & 21.3 \\
\hline
\end{tabular}

The data observed in day scholars that is the students who lived with their parents when seen in day scholar males showed overall independency rates where only 30 percent of the population were seen to have independent views when it came to parents being a help to them. When privacy invasion was raised 40 percent thought it was sometimes and pointed towards a mature behavioral trait but it constituted a very small section of the population. However, 46.7 percent of the population chooses to spent time with their friends other than their family which totally contradicts the point raised in hostellers on surprise visit where the notion was greatly supported. Moreover, 13.3 percent of the population sometimes introduced their parents with their friends in this study population. Whereas, 10 percent was seen indulged in lying which is high when compared to hostellers which was 3.3 percent and none of the males and females respectively. If caught in malpractice only 40 percent independency rate were observed.

(C) The International Journal of Indian Psychology, ISSN 2348-5396 (e) | ISSN: 2349-3429 (p) | 115 
Whereas when the day scholar females were assessed with the same conditions 53.3 percent independence rate were observed when the malpractice points were raised. 76.7 percent independency rates similar to those of males were observed here. However, 53.3 percent of the study population skipped their family over friends. A moderate rate of, 36.7 percent of independence or mature thinking was seen when the privacy invasion was questioned. Overall independency was observed to be 40 percent here in day scholar females.

\section{RESULT AND DISCUSSION}

The results states that the comparison between the decision making abilities observed between males/females living with their parent (day scholars) and those who don't (hostellers). On a broader view of comparison (Figure 1), it can be seen that independency in decision making is more observed in hostellers may it be a male or female. Whereas conclusion of the decision made was influenced by their parents are seen almost in a linear fashion in all the categories except hosteller males (which may differ on individual prospective). Selfish nature in decisions made are least observed in hosteller females than the others.

In this study largely seen that an influence of parents in decision can be observed in day scholars with these statistics. This influence largely increases the independency in decision making ability whereas vice versa case was being observed in the hosteller population or with the students who stayed away from their homes. Exceptions to this study always may exist. However, the adults coming under the category of hostels finally frame the decision according to them but may take views and opinions from their parents whereas it can be said that for day-scholars most of the decision are framed by their parents. This also states that the independency level in an adult increases when he/she is staying a far distance away from his/her parents. The study suggests that there should be a greater amount of independency level in adults of all categories and it was also seen so. The selfishness level in decisions made by adults should be less. Dependency on the parents for decisions should be present at a certain level as parents always make decisions in favour of the child's good future and have experience when it comes for a decision to be made in a different and a tuff situation. Whereas the results interpreted show independency level in decision making is high in all categories that states that the adults are mature enough to make small decisions by their own (this may vary with individual's experience of decisions he or she has made and thinking).

\section{CONCLUSION}

From the above performed analysis the researchers conclude that, the hostellers are more independent in their decision making abilities and tend to take less support from their parents in the decision they make as compared to day scholars. Whereas the individual thinking may vary and contradict the statement (at some point of times) as it depends on each person's decision making ability. Thus the distance plays a major role when the decision making ability of an adolescent teenager is to be judged. Our analysis showed that adults living far from their parents 
had slightly more independency in taking their own decisions compared to the ones who live with their parents.

Figure 1: Percentage Distribution of Overall independency in decision making across

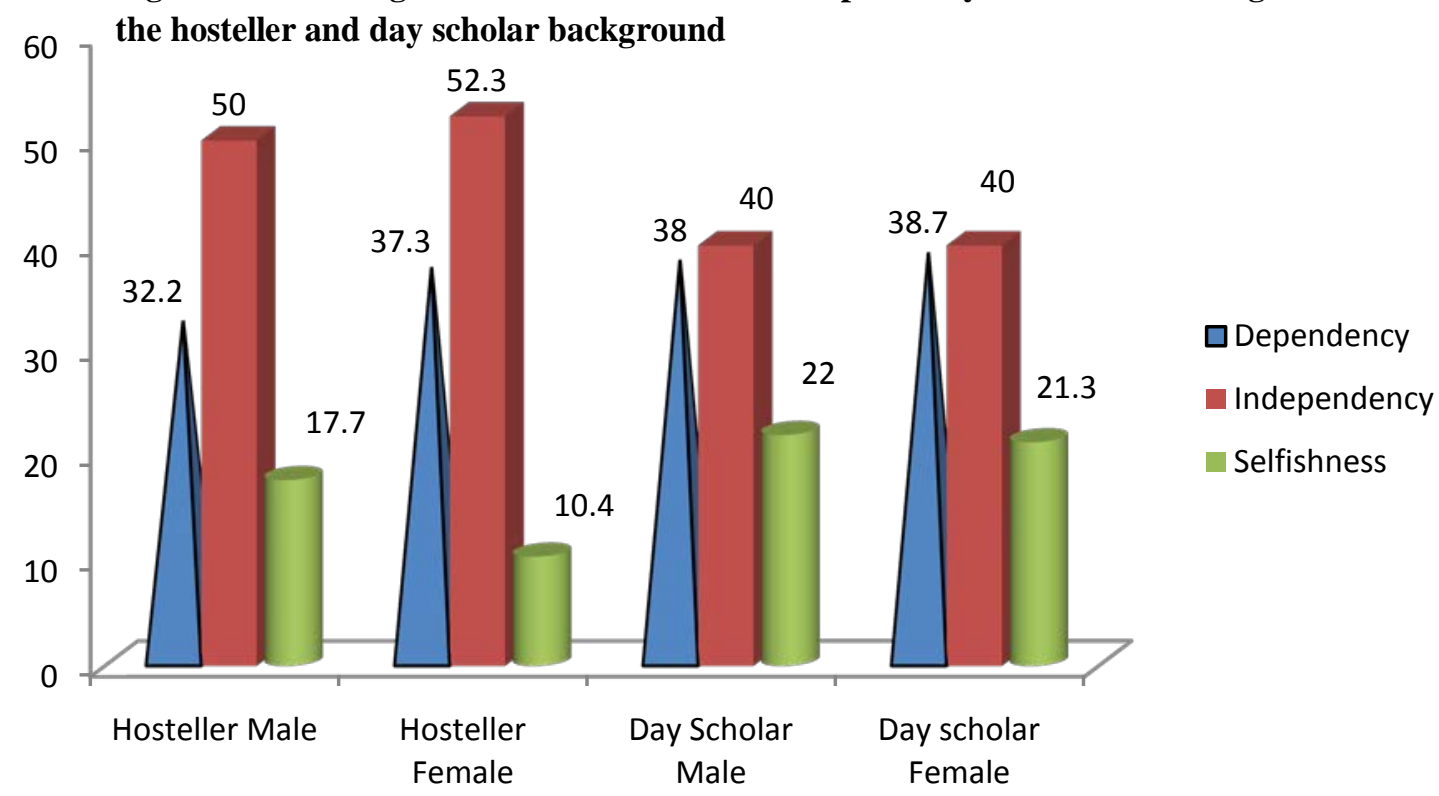

\section{Acknowledgments}

The author appreciates all those who participated in the study and helped to facilitate the research process.

\section{Conflict of Interests}

The author declared no conflict of interests.

\section{REFERENCE}

Cook, JD. (2014), “Independent decision making”, Singular value consulting. http://www.johndcook.com/blog/2014/03/21/independent-decision-making/

Debate Society. (2016), "Should teens be given the right to make their own decisions?" http://www.debate.org/opinions/should-teens-be-given-the-right-to-make-their-owndecisions

Lundberg, S., Romich, J. and Tsang, KP. (2007), “Decision Making by Children”, Institute for the Study of Labor, IZA Discussion paper series No. 2952. http://www.ftp.iza.org/dp2952.pdf

Myatt, M. (2012), “6 tips for making better decisions”, Opinions expressed by Forbes. http://www.forbes.com/sites/mikemyatt/2012/03/28/6-tips-for-making-betterdecisions/\#dc21e689f54b

Patrick, JH., Steele, JC. And Spencer, SM. (2013), “Decision Making Process and Outcome”, Journal of Ageing Research, Volume 2013 (2013), Article ID 367208, 7 pages. http://www.hindawi.com/journals/jar/2013/367208/ 
Independence in Decision Making: Considering the Distance between Parents and Their Children

Payne, JW., Bettman, JR. and Johnson, EJ. (1993), “The adaptive decision maker”, Cambridge University Press, NY: USA.

http://www.catdir.loc.gov/catdir/samples/cam031/92021581.pdf

Tucker-Ladd, CE. (2004), “Learning independent decision-making”, in Psychological Self-Help. http://www.psychologicalselfhelp.org/Chapter8/chap8_38.html

How to cite this article: K Kadam, A Bajpai, J Balamurugan (2016), Independence in Decision Making: Considering the Distance between Parents and Their Children, International Journal of Indian Psychology, Volume 3, Issue 4, No. 68, ISSN:2348-5396 (e), ISSN:2349-3429 (p), DIP:18.01.202/20160304, ISBN:978-1-365-39398-3

(c) The International Journal of Indian Psychology, ISSN 2348-5396 (e)| ISSN: 2349-3429 (p) | 118 